$\mathrm{J}($ (৫)

\begin{tabular}{||l|c|c||}
\hline Received 27.09.2020 & & JOTS \\
\hline \hline Accepted 04.10.2020 & Research Article & $5 / 1$ \\
\hline \hline Published 10.01.2021 & & $2021: 161-194$ \\
\hline
\end{tabular}

İzmir depreminde (2020) hayatını kaybedenlerin aziz hatırasına ...

\title{
Türkiye'deki Manihey Harfli Eski Uygurca Neşirler İçin Harfçevrim ve Yazıçevrim Kılavuzu
}

\section{A Manual of Transliteration and Transcription for Old Uyghur Editions with the Manichean Script in the Turkey}

\author{
Erdem UçAR* \\ Friedrich-Schiller-Universität Jena (Jena/Germany) \\ E-mail: erdem.ucar@uni-jena.de
}

Transliteration (< trans + literation) is the spelling of words from one script with characters from the another. Transcription (< trans + scription) is the representation of the sound of words in a language using any set of symbols you may care to invent or borrow for the purpose. The article deals with the characters of transliteration and transcription for editing of Old Uygur texts with the Manichean script in Turkey.

Key Words: Old Uyghur, edition, the Manichean script, transliteration, transcription.

ORCID ID: 0000-0002-0039-9619. 


\section{J(৫)}

\section{Giriş}

İran'daki bir Parth ailesine mensup olan Mani (216-276), Hiristiyanlık, Zerdüştlük ve Budizm'deki bazı unsurları gınostik görüşlerle birleştirip Maniheizim isimli bir dini İran'da tesis etmişti. Bögü Kağan'ın (759-779), Çin vasitasıly Maniheizim'i Uygurlar arasında 762'de devletin resmî dini ilan etmesinin ${ }^{1}$ (Tekin, 1963) ardından Eski Uygur dili ve edebiyatı sahasında Manihey çevreye ait bir literatür oluşmuştur.

Türkçe Manihey literatürün filologlar tarafından incelenmeye başlanması geçen yüzyılın başından itibaren, ağırlıklı olarak F. W. K. Müller, W. Radloff, K. Foy, A. von Le Coq, W. Bang, T. Haneda, R. R. Arat ve A. von Gabain sayesinde olmuştur. Erken dönemin temsilcilerinin ardından bugün hayatta olmayan J. P. Asmussen, Shimin Geng, J. R. Hamilton, H. J. Klimkeit, L. V. Dmitriyeva, L. Yu. Tuguşeva gibi uzmanlar da Türk Manihey literatürüyle ilgilenmiştir. Günümüzde P. Zieme, T. Moriyasu, L. Clark, A. van Tongerloo, J. P. Laut, J. Wilkens, Z. Gulácsi, M. Knüppel, Z. Özertural, vs. gibi isimler Manihey çevreye ait Eski Uygurca belgeleri incelemeye devam etmektedir.

Bugüne kadar Türkçe Manihey çevreye ait belgeler üzerine yapılan çalışmaları uzun uzadıya burada zikretmeyeceğim. Bu konu için Eski Uygurca kaynakçasına (Volker et al., 2000) ile Uigurisches Wörterbuch'un şimdiye değin neşredilen ciltlerinin kaynakça kısımlarına bakılabilir. ${ }^{2}$ Ancak burada bazı temel çalışmalardan kısaca bahsetmek belki faydalı olabilir.

F. W. K. Müller, ilk kez Manihey harflerinin seslik karşılıklarını gösteren bir liste vermiş ve Manihey literatürün incelenmesi konusunda önemli bir adım atmıştır (1904a: 2). Ardından, A. von Le Coq'un MIK III 35a-b (TM 327) numaralı parçayı neşretmesi, dikkatlerin Manihey harfli metinler üzerine yoğunlaşmasını sağlamıştır (1909: 1050-1052, Taf. IX), zira bu parçada Türk Runik harflerinin karşıllı̆ı Manihey harfleri ile gösterilmiştir. Runik harfler o dönemde artık çözüldüğü için Manihey yazılı belgelerle ilgileneceklere bu belge faydalı olmuştur.

Bögü Kagan'ın Maniheizim'i resmî devlet dini ilan etmesiyle ilgili bilgiler Uygur harfli U 72 ve U 73 (TM 276a-b) numaralı parçalarda mevcuttur. İki parçanın neşri için bk. Clark, 2017: 134-147.

2 Manihey literatür üzerine Çin'de yapılan çalışmalar için bk. Ariz, 2011: 193-22 ve Semet, 2011: 223-234. 


\section{ग(৫)}

Zieme, doktora tezinde Almanya'ya getirilen Manihey yazılı metinlerin yazım ve dilbilgisel özellikleri hakkında önemli bir çalışma ortaya koymuştur (1969). Tezde, Manihey harfli M 132 a II, M 365, U 121, U 122 a-b, U 131, U 140, U 219 a-b, U 230 a, U 241 a-c, U 296, U 297 numaralı parçaların neşri de verilmiştir.

Moriyasu, Uygur Maniheizim'i hakkında Uygurca belgelere dayanan bir monografi hazırlamıştır. Monografide, Manihey Uygur çevreye ait metin neşirleri de bulunmaktadır. Eserin Japonca aslı için bk. Moriyasu 1991 ve Almanca tercümesi için bk. Moriyasu 2004.

Manihey çevreye ait Almanya'daki belgeler Wilkens (2000) tarafından kataloglanmıştır. Katalogda, Manihey çevreye ait bütün Eski Uygurca belgelerin listesi verilmiş ve belgeler tavsif edilmiştir. Tavsif edilen bu parçaların bir kısmı daha önce Zieme tarafindan Berliner Turfantexte serisinin beşinci cildinde neşredilmiştir (1975).

Clark'ın Corpus Fontium Manichaeorum: Series Turcica serisi altında neşrettiği Manihey çevreye ait Eski Uygurca metinlerin toplu neşri dikkate değerdir. Şimdiye değin seride iki cilt çıkmıştır. Çıkan ilk ciltte (aslında serinin II. cildi) Xwāstwānîft ve Mani'ye Büyük İlahi (Pothi-Book) gibi Manihey çevreye ait önemli iki metnin neşri varken (Clark 2013), ikinci ciltte (aslında serinin III. cildi) ise manastır metinlerinin neşri bulunur (Clark 2017). Serinin öğreti metinlerinin neşriyle ve metinlerin sözlüğüyle tamamlanması pilanlanmaktadır. Böylece Manihey çevreye ait metinlerin hepsinin neşrine ve sözlüğüne kavuşulacaktır.

Manihey Türk edebiyatına ait ürünlerin tasnifi üzerine birkaç öneri sunulmuştur. Wilkens (2000: 13-20), Manihey çevreye ait metinleri dokuz guruba ayırmaktadır: 1. Tarihî metinler, anlatılar ve efsaneler; 2. Dinî vaazlar ve vecizeler; 3. Öğreti risaleleri; 4. Kozmolojik ve mitolojik metinler; 5. Kilise metinleri; 6. Ayin metinleri; 7. Karışık metinler; 8. Şahsî belgeler; 9. Belirsiz parçalar.

En son tasnif, yine Clark tarafından yapılmıştır (2017: 1-4). Onun tasnifine göre, Manihey Türk edebiyatına ait Uygurca metinler içerikleri bakımdan üç temel guruba ayrılmıştır:

\section{Ayin Metinleri (Liturgical Texts)}

Bu gurupta, Maniheizim'in ritüellerinde kullanılan çeşitli istiğfar duaları ile bazı ilahi parçaları bulunmaktadır. İstiğfar metinlerinin en meşhuru Londra, 


\section{ग(৫)}

Berlin ve St. Petersburg'da nüshaları olan Xwāstwānifft'tir. İlahi metinleri içinde de en meşhuru Mani'ye Büyük Illahi'dir (Pothi-Book). Ayin metinlerinin hepsi Clark 2013’te neşredilmiştir.

\section{Manastır Metinleri (Ecclesiastical Texts)}

Bu parçalar içinde çeşitli seremonilerde sunulan kutsama metinleri, tarihî kayıtlar, mektuplar, anlatılar, çeşitli ketebe kayıtları ile kiliseyle ilgili metinler bulunur. Manastır metinlerinin hepsi Clark 2017'de neşredilmiştir.

\section{3. Öğreti Metinleri (Doctrinal Texts)}

Bu metinler, Mani'nin kendi eserleri, vaazları, dinin ilkelerinin yer aldığı anlatılardan meydana gelmektedir.

Manihey literatürden kısaca bahsettikten sonra Manihey yazısına artık dönebiliriz. Manihey yazının kaynağı konusu tartışmalıdır. Bir tarafta, yazının Aramî alfabesinin bitişik olmayan türü ile Süryanî alfabesinin bitişik türü arasındaki geçiş şekillerinden birini temsil eden Estrangelo yazısından çıktığ1 görüşü (Müller, 1904a ve 1904b; Skjaervø, 1996: 519, 530-531; Tekin, 1984: 7) varken, diğer tarafta Lidzbarski'nin (1916: 1213-1222) ilk kez ortaya koyduğu ve daha sonra Henning (1958: 73), Sundermann (1985: 101-113) ve DurkinMeisterernst (2014: 36-37) gibi İranistler tarafindan da kabul görüp geliştirilen başka bir görüş daha vardır. Bu görüşe göre, Mani muhtemelen ticaret yoluyla Suriye'deki Palmira yazısının bir varyantını kendi ülkesine getirmiş ve bu yazıyı kendi diline adapte edip Maniheizim'in temel eserlerini bu yazıyla yazmış olmalıdır. Dolayısıyla, Manihey yazının kökeni MÖ. 100-MS. 300. yıllar arasında Suriye'de kitabelerde kullanılan Sami kökenli Palmira (Palmyrene) yazısına dayanmaktadır. Bu konuda en son olarak İranist Durkin-Meisterernst, Manihey yazının Palmira yazısından nasıl oluşturulduğunu ayrıntılı paleografik açıklamalarla göstermiştir (2000: 161-178).

Manihey yazısı, Partça ve Soğdça gibi Orta İran dilleri dışında Eski Uygurca ve Toharca B (Küşen dili) gibi dillerin yazımında da kullanılmıştır. Uygurlar da bu yazıyı Soğdlulardan ödünç almış ve yazıyı kendi dillerine uyarlayıp kullanmıştır. Clauson, Orta Asya'daki Soğdlu misyonerlerin Manihey Soğd yazısını model alarak bu yazıyı Eski Uygurcaya uyarladığını düşünmektedir (1962: 114-115). Yani ona göre, yazının uyarlama işini Soğdlu rahipler yapmıştır. Ancak 


\section{J(৫)}

Soğdlu rahiplerin Eski Uygurcayı veya o dönemin Türkçesini ne kadar bildiği konusu net olarak belli değildir. Belki de yazıyı uyarlayanlar Soğdçaya vakıf Uygurlardı. Dolayısıyla bu konuda kesin bir şey söylemek kolay değildir.

Manihey Soğd yazısında Manihey harflerin adları konusunda bazı belirsizlikler vardır. Bazı harfler için aynı isimler kullanılmıştır, mesela B-B্ , Ğ-G, gibi. Bazı harflerin ise adı yoktur, mesela L, $\dot{P}$, J gibi (Durkin-Meisterernst 2014: 31-36). Aşağıdaki tabloda, harflerin isimleri kullanışl1lık amacıyla oluşturulmuş olup harflerin nihaî adlandırmasını taşıdığı iddiasında değildir. Harflerin adlandırılmasında Sami kökenli yazı sistemlerindeki harflerin bugün Türkçede bilinen isimleri esas alınmıştır. Böylece Uygur ve Arap yazısındaki harflerle Manihey yazısındaki harflerin kolayca karşılaştırılmasına imkân tanınmıştır.

Daha önceki makalemde, Türkiye'de neşredilecek Uygur harfli metinlerin harfçevrim ve yazıçevrimi için bir kılavuz önerisi sunmuştum (Uçar, 2020: 231250). Bu makalemde ise, Manihey harfli metinlerin harfçevrimi ve yazıçevrimi için bir kılavuz önerisi sunmaya çalışacağım. Sunacağım önerinin yeni olacağını tahmin ediyorum, zira şimdiye değin Manihey yazılı metinlerin harfçevrimi ve yazıçevrimi için Türkiye'de gelenekselleşen bir sistemin olmadığı malumdur.

Eski Uygurca metinlerin harf̧̧evriminin ve yazıçevriminin geçmişten günümüze değin nasıl yapıldığı ve dikkati çeken sorunların neler olduğu meselesi daha önce ele alınmıştı (Röhrborn, 2016 ve 2018). Ayrıca, Manihey çevreye ait bir metin neşrinde uygulanan harfçevrim ve yazıçevrim yöntemine de daha önce (Röhrborn, 2015b: 169-171) değinilmiștir. Manihey harfli metinlerin neşirlerinde uygulanan yöntem konusu için bu çalışmalara bakılabilir.

Tabloda, Manihey harfleri için "Titus Manichean" yazı tipinden faydalanılmıştır. Manihey harflerinin başta, ortada ve sondaki şekilleri ayrıca gösterilmemiştir. Harflerin farklı pozisyondaki şekillerinin ayrıntılı resimleri için bk. Fariwar-Mohseni-Najafi, 2005: 152-180.

II. Manihey Yazının Harfçevrim ve Yazıçevrim Tablosu

\begin{tabular}{|c|c|c|c|c|}
\hline No & Harf Ad1 & Orijinal Harf & Harfçevrim & Yazıçevrim \\
\hline \multirow[t]{3}{*}{1} & \multirow{3}{*}{ elif } & \multirow{3}{*}{ se } & \multirow{3}{*}{ A } & e (başta) \\
\hline & & & & a a (nadiren başta) \\
\hline & & & & a/e (ortada ve sonda) \\
\hline 2 & çift elif & & $\overline{\mathrm{AA}}$ & $\overline{\text { a (başta) }}$ \\
\hline
\end{tabular}




\begin{tabular}{|c|c|c|c|c|}
\hline & & אתא & & a (nadiren sonda) \\
\hline \multirow[t]{3}{*}{3} & \multirow{3}{*}{ elif+vav } & \multirow{3}{*}{ אחה } & \multirow{3}{*}{ AW } & o/u (başta) \\
\hline & & & & "ö/ü (nadiren bașta) \\
\hline & & & & o/u (nadiren ortada) \\
\hline 4 & elif+çift vav & $\overline{A N R}$ & $\overline{A \text { AWW }}$ & o (nadiren başta) \\
\hline 5 & elif+vav+ye & חNה & AWY & ö/ü (başta) \\
\hline \multirow[t]{2}{*}{6} & \multirow[t]{2}{*}{ elif+ye } & \multirow{2}{*}{ w } & \multirow[t]{2}{*}{$\overline{\mathrm{AY}}$} & é/1/i (başta) \\
\hline & & & & 1/i (nadiren ortada) \\
\hline \multirow[t]{2}{*}{7} & \multirow[t]{2}{*}{ ayın+ye } & \multirow{2}{*}{ هم } & \multirow[t]{2}{*}{$\overline{E Y}$} & é/1/i (başta) \\
\hline & & & & 1/i (nadiren ortada) \\
\hline 8 & vav & ^ & $\overline{\mathrm{W}}$ & o/ö/u/ü \\
\hline 9 & vav+ye & an & $\mathrm{WY}$ & ö/ü (ilk hecede) \\
\hline \multirow[t]{2}{*}{10} & \multirow[t]{2}{*}{ çift vav } & \multirow[t]{2}{*}{ an } & \multirow[t]{2}{*}{ WW } & $\begin{array}{c}\mathrm{o} / \ddot{\mathrm{o}} / \mathrm{u} / \ddot{\mathrm{u}} \\
\text { (nadiren ilk hecede) }\end{array}$ \\
\hline & & & & o/ö/u/ü (nadiren sonda) \\
\hline \multirow{3}{*}{11} & \multirow{3}{*}{ ye } & \multirow{3}{*}{ ○ } & \multirow{3}{*}{ Y } & é/1/i (ilk hecede) \\
\hline & & & & $\overline{1 / \mathrm{i}}$ \\
\hline & & & & $\mathrm{y}$ \\
\hline \multirow[t]{2}{*}{12} & \multirow[t]{2}{*}{ çift ye } & \multirow{2}{*}{$\bullet \bullet$} & \multirow[t]{2}{*}{$\overline{Y Y}$} & é/1/i (nadiren ilk hecede) \\
\hline & & & & 1/i (nadiren sonda) \\
\hline 13 & be & 드 & B & $\mathrm{b}$ \\
\hline 14 & çift noktalı be & $\ddot{\underline{u}}$ & $\underline{B}$ & $\overline{\mathbf{v}}$ \\
\hline 15 & çe & $r$ & $\bar{c}$ & $\overline{c ̧}$ \\
\hline \multirow[t]{2}{*}{$\overline{16}$} & \multirow[t]{2}{*}{$\overline{\mathrm{de}}$} & \multirow{2}{*}{$s$} & \multirow[t]{2}{*}{ 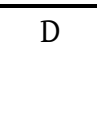 } & $\bar{d}$ \\
\hline & & & & $\overline{\mathrm{t} \text { (nadiren) }}$ \\
\hline \multirow[t]{2}{*}{17} & \multirow[t]{2}{*}{ çift de } & \multirow{2}{*}{ VI } & $\overline{\mathrm{DD}}$ & $\overline{\mathrm{d}}$ \\
\hline & & & & $\mathbf{t}$ (nadiren) \\
\hline 18 & dal & ? & D & $\bar{d}$ \\
\hline 19 & gayın & I & $\breve{G}$ & $\breve{g}$ \\
\hline & & $\delta$ & & q (nadiren ?) \\
\hline 20 & ge & 1 & $\bar{G}$ & $\mathrm{~g}$ \\
\hline & & $T$ & & k (nadiren ?) \\
\hline
\end{tabular}




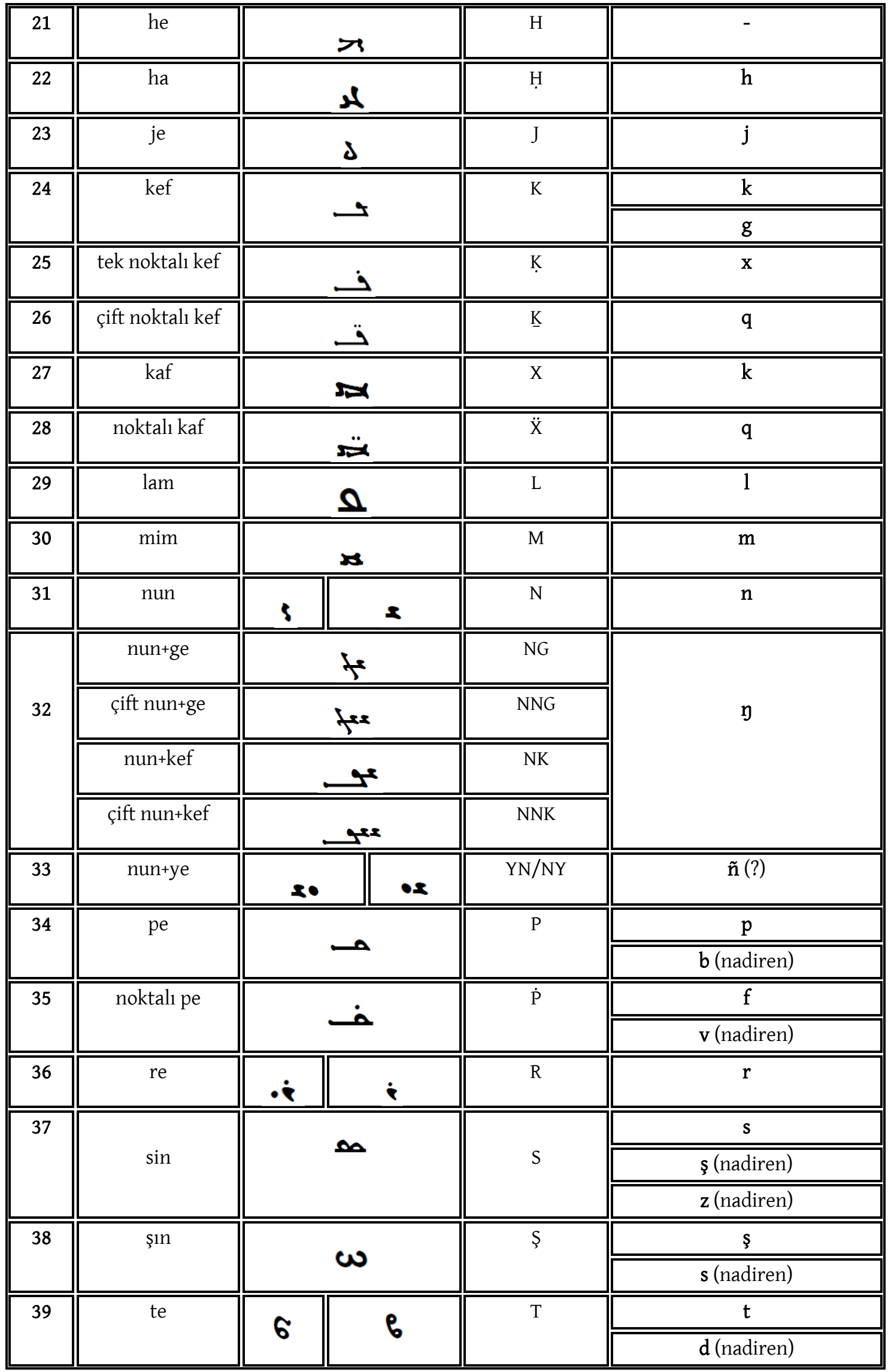




\begin{tabular}{|c|c|c|c|c|}
\hline 40 & ta & h & Ț & $t$ \\
\hline \multirow[t]{2}{*}{41} & \multirow[t]{2}{*}{ ze } & \multirow{2}{*}{8} & \multirow[t]{2}{*}{ Z } & $\mathrm{z}$ \\
\hline & & & & s (nadiren) \\
\hline 42 & çift noktalı ze & $\ddot{\rho}$ & $\underline{Z}$ & ç veya c (nadiren) \\
\hline
\end{tabular}

\section{Notlar}

Not numaraları, yukarıdaki tablonun sol sütununda yer alan rakamları göstermektedir:

Not 1-12. Manihey yazıda, Uygurca kelimelerdeki ünlülerin yazım geleneği Soğd ve Uygur yazısıyla aynıdır. Bunun için bk. Uçar, 2020: 238-240. Ayrıca, ^ A harfinin İranistlerin yaptı̆̆ 1 şekilde ' gibi bir sembol yerine bir harfle temsili hakkındaki açıklama için bk. Uçar, 2020: 245.

Not 5-6, 9. Uigurisches Wörterbuch'un harfçevrim ve yazıçevrim tablolarında Uygur, Soğd, Manihey ve Süryani yazılarında AWY'nin kelime başında oy-/uy-, WY'nin kelime ortasında ve sonunda oy/uy karşıllğıında, Uygur, Soğd ve Manihey yazılarında AY'nin kelime başında ey-, kelime ortasında ve sonunda ay/ey, Süryani yazısında ise kelime başında ay-/ey-, kelime ortasında ve sonunda ay/ey karşıllı̆̆ında olduğu söylenmiştir (Röhrborn 2010: XXXIII, XXXV-XXXVII). Ben de Uygur harfli metinlerin harfçevrim ve yazıçevrim tablosunda AWY, WY ve AY'yi aynı şekilde göstermiştim (Uçar, 2020: 236-237, 239-240). Bu ilkenin doğru olup olmadığından artık tam olarak emin değilim, zira harfçevrim ve yazıçevrim işaretleri tablosunda ünlü ve ünsüzlerin "birebir" karşıllk geldiği harf veya harfleri göstermeye çalıştım. Kılavuz özelliğindeki bir tabloda harf guruplarının karşılık geldiği hecelerin ayrıca gösterilmesi belki kafa karışıklığına sebep olabilir. Uigurisches Wörterbuch'ta AWY, AY ve WY'nin bir heceyi de gösterdiğinin belirtilmesinde şüphesiz didaktik bir gaye vardır. Orijinal metni okuyacakların bu harf guruplarında dikkatli olması gerektiği söylenmek istenmiştir. Uygur veya Manihey harfli metinde AASYLXAY asilğay şeklinde yazılan bir kelimenin sonundaki AY'nin bir ünlüyü değil, ay şeklinde bir heceyi gösterdiği açıktır. TWYMAX tuymaq şeklinde yazılan bir kelimenin ilk hecesindeki WY harflerinin bir ünlüyü göstermediği bellidir, zira kalın sırada yazılmış bir kelimede WY'nin /ö/ veya /ü/ karşılığında olamayacağını nâşirin bilemeyeceği asla düşünülemez. AYÇYNDA içinde şeklinde yazılan kelimenin başındaki AY'nin ey şeklinde bir hece 
karşılığında olmadığını Eski Türkçeye aşina olan nâşirin ilk bakışta fark edeceğinden şüphe yoktur. ${ }^{3}$ Sonuç itibariyle, kılavuz olarak hazırlanan bir tabloda AWY, AY ve WY'nin bir hece karşılı̆̆ında olabileceğinin belirtilmesine gerek olmadığı söylenebilir.

Not 3. Erken döneme ait Soğd ve Uygur harfli metinlerde fazlalık elif yazımı (hypertrophes Alif) bilinmektedir (Fedakâr, 1991: 92-94). Benzer şekilde, Manihey harfli metinlerde de kelime ortasında $\mathbf{a W}$ yazımı görülüyor. Bk. U 46a r9-10 (neşir $\rightarrow$ satır 78-79).

Not 7. a EY yazımı, Uygurca kelimelerde kelime başında /1/, /i/ ve /é/ ile nadiren ortada /1/ ve /i/'nin gösteriminde kullanılır (Zieme, 1969: 20). Bunun dışında ayın harfinin tek başına kullanımına sadece alıntı sözlerde rastlanır.

Not 10, 12. Manihey Soğdça metinlerde W ve $Y$ harflerinin kelime ve satır sonunda WW ve $\bullet Y Y$ ş̧eklinde çift yazımı görülüyor. Aynı imlâ özelliğine Manihey Uygur yazısında da rastlanır. Bu tür çift yazımlarda seslik bir özellik aranmamalıdır. Daha geniş bilgi için bk. Knüppel, 2002: 45-52.

Not 13-14. Manihey yazıda /b/ ve /v/ için iki farklı harf kullanılmıştır: ㄴ B ve $\ddot{\underline{B}}$ B. Sir G. Clauson, Runik harfli metinlerde kelime ortasinda ve sonunda B ile yazılan harfin aslında /v/ karşıllı̆̆ında olabileceğini düşünmüştür. Daha sonra bazı filologlar da bu görüşü kabul etmiştir. Burada akla gelen ilk soru, birçok ünsüzü kalın ve ince sırada olmak üzere iki farklı şekilde gösterebilen Runik yazının /v/ ünsüzü için neden ayrı bir işaret kullanmadığı sorusu olacaktır. Yazıda bu imkân olabilirdi, ama Runik yazı neden /v/ için ayrı bir işaret kullanmamıştır? Sanıyorum ki bu soru, Clauson ve takipçilerinin de kolayca cevaplayabileceği bir soru değildir. Aşağıda, örnek metinler bölümünde neşrini sunduğum Manihey harfli U 34 numaralı parçada 'su' anlamına gelen kelimenin hem SWB sub (neşir $\rightarrow$ satır 47) hem de SWB suv (neşir $\rightarrow$ satır 48) şeklinde yazıldığı görülüyor. İki farklı imlânın aynı metinde görülmesi ilginçtir. Aynı şekilde MIK III 201 I numaralı Manihey harfli parçada Clauson'un ve onun takipçilerinin Runik harfli metinlerde yavlaq olarak düşündüğü kelimenin YABLAẌ (r10) şeklinde yazıldığı (neşir $\rightarrow$ satır 59), yani açıkça /b/'li olduğu

\footnotetext{
Uigurisches Wörterbuch'ta görebildiğim kadarıyla AY'nin kelime başında ay-/ey- olduğunu gösteren sadece tek bir tanık vardır: eymenç<ç>i (Röhrborn, 2017: 351).
} 
görülmektedir. Yazıcının B için noktaları koymayı unuttuğunu söylemek işin kolayına kaçmak olacaktır. Uygur harfli metinlerde bazı kelimelerin hem /b/'li hem de /v/'li şekilleri görülebilmektedir. Mesela, qabuy qavuy, qabşa- qavşa-, yalbar- yalvar-, vs. Bu konuda daha geniş açılamaları başka bir makaleme bırakıp kısaca şunu söyleyebilirim: Eski Türkçenin ağızları ile bu ağızların yazı diline tesiri konusundaki bilgilerimizin fazla olduğu söylenemez. Dolayısıyla, Manihey yazıda B harfinin aynı zamanda /v/ karşıllğında olduğunu söylemek mümkün değildir.

Not 13-14, 24-26, 27-28, 34-35, 41-42. Manihey yazıda, ünsüzleri gösteren bazı harflerin gövdesi aynıdır. Yazı, aynı gövdeye sahip harflerde harfin üzerine tek veya çift nokta koyarak harfler arasında fark sağlamıştır. $=$ ت $\mathrm{B}-\underline{B}, \boldsymbol{\longrightarrow}$

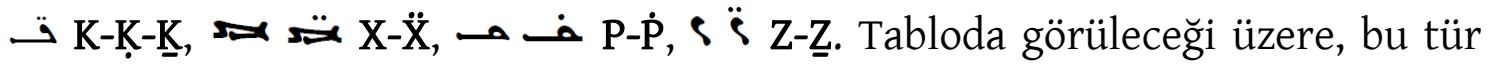
harflerin harfçevrim işaretleri için Latin yazısında aynı gövdeye sahip olanlar tercih edilmiştir. Böylelikle metni okuyacaklar harfin asliyla daha kolay irtibat kurabilecektir. Ayrıca, orijinalinde üstünde çift nokta bulunduran harflerin harfçevrimi altta çizgiyle gösterilmiştir: $\underline{B}, \underline{\mathbf{K}}, \underline{\mathbf{Z}}$. Sadece $\ddot{\sim} \ddot{\mathbf{X}}$ ve $\dot{\mathrm{P}}$ harflerinin harfçevriminde noktalar, noktasının sayısına göre üstte verilmiştir.

Not 16-18. Manihey Soğdça metinlerde $\ \mathrm{D}$ harfi sedalı sızıcı diş ünsüzü /ḍ/

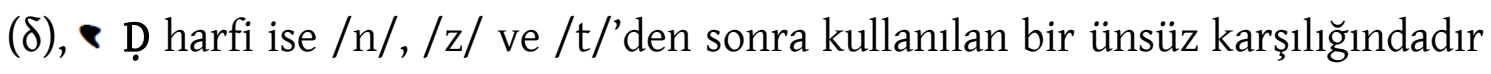
(Fariwar-Mohseni-Najafi, 2005: 129-130). Manihey Uygur yazısında ise, \ D harfi nadir olarak kullanılırken, bunun yerine metinlerde hemen hemen her zaman $\mathbf{S}$ D harfi kullanılmıştır. İki harfi birbirinden ayırmak amacıyla çalışmamızda $~ \mathbf{D}$ harfinin harfçevrimi ve yazıçevrimi için Uigurisches Wörterbuch'taki (Röhrborn, 2010: XXXVI) gibi altı noktalı Ḍ/ḍ tercih edilmiştir. Ancak bu gösterimde $\mathbf{P}$ harfinin seslik durumu dikkate alınmamıştır, sadece iki harf arasında ayrım gözetmek için böyle bir yol izlenmiştir. Dolayısıyla, bu harfi Arap harfli Eski Türkçe metinlerdeki ذ̇zel harfi ile karıştırmamak gerekiyor. Üstelik /d/ ve /ḍ/ ünsüzlerinin Eski Türkçe kelimelerdeki seslik değeri ve hangi harflerle temsil edildiği meselesi tartışma konusudur. Bu konuda daha geniş bilgi için bk. Erdal, 2004: 67-69.

Not 17. Manihey Uygur yazısında \ل DD şeklindeki çift yazımın seslik bir değeri bulunmaz (Zieme, 1969: 21). 


\section{ग(๑)}

Not 19-20. ‡े Ğ ve † $\mathrm{G}$ harflerinin gövdeleri birbirine çok benzemektedir.

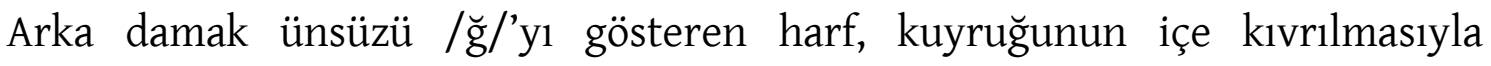
diğerinden ayrılmaktadır. Ancak bundan daha önemli mesele, bu iki harfin aynı zamanda sedası /q/ ve /k/ ünsüzlerini de gösterip göstermediğidir. Manihey yazısı, Uygur yazısından farklı olarak /k/ ve /g/'yi ya da /q/ ve / ̆ /'yi birbirinden ayırabilmektedir. $\mathrm{Bu}$ anlamda, Uygurca metinlerin okunuşunda Manihey yazısının anahtar rolünden bahsedilebilir. Ancak Xwāstwānïft'in Londra yazmasına bakıldığında, \{-sXk\} ekinin bazen G/K ile bazen de X/Ğ ile yazıldığ görülüyor. Mesela, XYGWRSWG kigürsüg (229), AANÇWLASYK ançulasıq (222), vs. Aynı şekilde örnek metinler başlı̆̆ altında neşrini sunduğum Xwāstwānifft'in Londra yazmasına ait parçada alqansıq kelimesi AALẌANSYĞ alqansı̆̆ (neşir $\rightarrow$ satır 11) şeklinde yazılmıştır. Clark, Manihey harfli metinlerin neşrinde ekin hangi harfle yazıldığına bakmaksızın ekin ünsüzünü her zaman sedasız okumayı tercih ettiği için, bu kelimeyi de alqansıq olarak okumuştur (2013: 88, 108). Erdal ise, Uygur harfli metinden Manihey harflerine metn kopyalayan müstensihin artık canlılığını yitiren ekin gerçek telaffuzunu unuttuğunu düşünmektedir (2004: 301-302). Gerçekten de Runik harfli metinlerde \{-sXk\} ekinin her zaman K/Q ile yazıldığı bilinmektedir. Ancak Erdal'ın tespiti şöyle bir soruyu akla getiriyor. Uygur harfli kaynaktan Manihey harflerine metni aktaran müstensih ekin ünsüzünün sedalı veya sedasız olup olmadığını nasıl anlayacaktır? Zira Uygur yazısı, /k/ ve /g/ ile /q/ ve / $\breve{g} /$ arasında her zaman bir ayrım gözetmemektdir. Netice olarak Manihey Uygur yazısında, $\delta$ g ve $t \in$ harflerinin ekseriyetle / $\breve{g} /$ ve /g/ karşıllı̆ında olduğu kabul edilmeli, ama bunların yazmaya göre bazen /q/ ve /k/ karşllığında olabileceğine de ihtimal verilmelidir. Dolayısıyla kelimelerin okunuşunda etimolojik ilkenin esas alınması gerekmektedir. Ayrıca krş. Not 24.

Not 21-22. Manihey Soğdça metinlerde $ح \mathrm{H}$ ve $\mathbf{H}$ Ḥ iki farklı harf olarak gösterilirken (Fariwar-Mohseni-Najafi, 2005: 129-130), Uigurisches Wörterbuch'ta Uygurca metinler için $>\mathbf{H}$ harfi, s H Ḥ’nin farklı bir şekli olarak kabul edilmiştir (Röhrborn, 2010: XXXVI). Manihey Soğdça metinlerde $>\mathbf{H}$ harfi herhangi bir seslik değere sahip olmayıp sadece satır doldurucu bir işaret olarak kullanılmıştır.

\&f $\mathrm{H}$ harfine ise alıntı sözlerde veya işaret zamirinde rastlanabilir (FariwarMohseni-Najafi, 2005: 129-130). Aynı durum Manihey çevrenin Uygurca 


\section{ग(৫)}

metinleri için de geçerlidir. Uygurca metinlerde $\neg \mathrm{H}$ harfi satır doldurucu harf olarak kullanılmıştır ve harfin birkaç varyantı mevcuttur. Daha geniş bilgi için bk. Knüppel, 2014: 163-165. Manihey harfli metinlerin neşrinde, seslik bir değere sahip olmayan bu harfin sadece harfçevrimde gösterilmesi, ama yazıçevrime yansıtılmaması gerekmektedir. of $\mathrm{H}$ harfi ise, Uygurca metinlerde sadece alıntı sözlerde görülür. İki harfin birbirinden ayrılması gerekmektedir.

Not 23. $\Delta$ J harfi, Uygurca metinlerde sadece alıntı sözlerde kullanılmıştır.

Not 24. $\rightarrow \mathrm{K}$ harfi, daha çok /k/ karşıllı̆̆ında olmakla beraber bazen /g/ karşıllı̆̆nda da olabilmektedir. Mani'ye Büyük İlahi veya Uygurca literatürde bilinen adıyla Pothi-Book'ta $\rightarrow \mathrm{K}$ harfinin bazen /g/ karşıllğında olduğu görülüyor. ${ }^{4}$ Mesela, Pothi-Book'a ait U 87 numaralı Manihey harfli parçanın ön yüzünün 5. satırında şimdiye değin Eski Türkçe metin neşirlerinde emgeklig şeklinde okunan kelime AMKAKLYG emkeklig şeklinde yazılmıştır. Aslında bu yazım özelliğine Xwāstwānift'in Londra yazmasında da rastlanmaktadır. Eski Türkçe neşirlerde kértgün- şeklinde okunan fiil, bu yazmada $\mathrm{K}$ ile yazılmıştır: KYRTKWNMADMZ kértkünmad(i)m(i)z (Or. 8212/178, neşir $\rightarrow$ satır 71). U 54 numaralı parçanın ön yüzünün ilk satırındaki BAGRW yazımı (neşir $\rightarrow$ satır 86) bekrü mü yoksa begrü mü okunacaktır? ${ }^{5}$ Clauson, kelimeyi tanıklanmamış *bekerfiilinin ünlü zarffiil eki almış şekli saymakta ve kelimeyi bekrü olarak okumaktadır (1972: 328b). Erdal ise, yazmada /k/ ve /g/'lerin birbirine karıştırıldığını düşünmektedir (1991: 175). Yine U 54 numaralı parçanın ön yüzünün 7. satırında \{-gAy\} ekinin $\mathrm{K}$ ile yazıldığı görülüyor: AYLTKAYY éltkey (neşir $\rightarrow$ satır 92). Aslında /k/ ve /g/ ünsüzleri Eski Türkçenin yazımında kullanılan alfabelerden sadece Runik, Manihey, Brāhmī ve Tibet alfabelerinde birbirinden ayrılmaktadır, ama Uygur ve Arap yazılarında iki ünsüzü birbirinden ayırmak mümkün değildir. Bu nedenle karşılaştırmalı Türk dilleri yönteminden yararlanmak zorunluluk olur (Erdal 1991: 172-173). Netice olarak, böyle

4 Uygurca parçanın yazım özellikleri bakımından epey sıra dışı olduğu söylenebilir. Metnin yazım özellikleri hakkında ayrıntılı bilgi için bk. Clark, 1982: 161-165; 2013:151-152. Erdal, /k/ ve /g/'nin bu yazmada biribiri yerine yazımını önemsiz görmekte, harflerin biribirine karıștırılmış olabileceğini düşünmektedir (1991: 754).

5 Wilkens, parçada sedalı ve sedasız ünsüzlerin yazımında seyrek olarak görülen bir karışıklıktan bahsetsetmektedir (2000: 140). 


\section{ग(৫)}

durumlarda etimolojik okuyuş ilkesinin benimsenmesi tek çare gibi gözükmektedir. Ama bazı durumlarda bu imkânlar yine de yeterli olmayabilir. Böyle durumlarda belki de Erdal'ın yaptığı gibi ünsüzün kesin okunuşu verilmek yerine ünsüz K ile gösterilmelidir. Mesela, ozKur- 'kurtarmak' (Erdal 1991: 751), körKit- 'göstermek' (Erdal 1991: 778), vs.

Not 33. Clauson, Runik harfli metinlerde /ñ/'li olarak tanılanan kelimelerin Manihey harfli metinlerde bazen N, bazen NY ve bazen de YN ile yazılsa da bunların /ñ/'li okunması gerektiğini düşünmektedir (1962: 118). Zieme ise, Manihey harfli metinlerde sadece NY şeklindeki yazımın / ñ/'li okunabileceğini, N'li veya Y'li yazımların /ñ/'li okunamayacağını ifade eder (1969: 36-37). ${ }^{6}$ Röhrborn, Runik harfli metinlerde /ñ/'li olarak tanıklanan kelimelerin Manihey harfli metinlerde NY veya $\mathrm{Y}$ şeklindeki yazımına bakmaksızın farklı okunamayacağını ifade eder ve Clauson'un görüşüne katılır. Bununla beraber, Uygur yazısında Sanskritçe alıntılarda /jñ / ünsüz gurubunun muhafaza edildiğini belirtir. Röhrborn, Eski Türkçenin ağızlarında / ̃̃/ ünsüzünün bir ölçüt olarak alınamayacağı fikrindedir (1983: 298-305). Uigurisches Wörterbuch'ta /ñ ünsüzünün sadece Soğd, Uygur ve Manihey yazılarından tespit edilebileceği gösterilmiştir. Buna göre, $\mathbf{N}$ harfi y- ağzında alıntı sözlerde / $\tilde{n} /, \mathbf{N Y}$

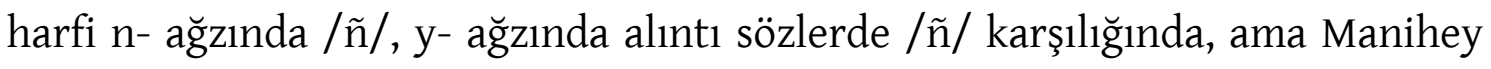

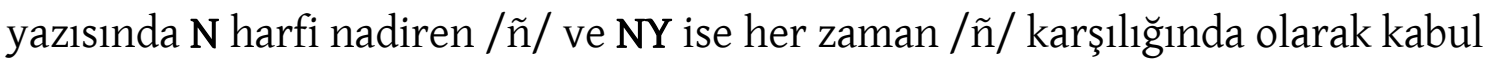
edilmiştir (Röhrborn 2010: XXXIV-XXXV). Hamilton, Bazin gibi Runik yazıda NY'nin /yn/ veya /ny/ karşıllı̆ında olabileceğini düşünmekte ve bunun nedenini ağızların karışmasına bağlamaktadır (1971: 63). Erdal, muhtemelen ünsüzün / ñ / > /n/ > /y/ değişimi geçirerek metinlerde yaşadığını düşünmektedir (2004: 7172). Clark ise, Manihey harfli metinlerin neşrinde NY veya YN yazımını /ñ/ ile, ama N ve Y yazımını ise /n/ ve /y/ ile okumuştur: ANYĞ añ qoñqa (2017: 226), AAYYĞ ayı̆̆ (2013: 116), çYĞAY çı̆̆ay (2017: 55), vs. Eski Türkçe /ñ/ ünsüzü hakkındaki deliller çok güçlü değildir. Aslında bu ünsüzü barındıran kelimelerin sayısı da fazla sayılmaz. ${ }^{7}$ ñ ünsüzü için müstakil bir işaret sadece Runik yazıda bulunur, ancak Uygur ve Manihey yazılarında /ñ/ ünsüzü için ayrı

\footnotetext{
Ayrıca krş. Hazai \& Zieme, 1970: 132-139.

Bu ünsüzün bazı Sibirya gurubu Türk dillerindeki /ń/ ünsüzü ile kıyaslanması biraz şüphelidir, zira bu Türk dillerindeki genizsil sedalı ön damak ünsüzü /ń/ aynı zamanda kelime başında da görülebilmektedir.
} 
bir harf yoktur (Erdal 2004: 71). Manihey yazıdaki NY veya YN yazımları bir ligatür olarak kabul edilecek olunursa, belki Manihey yazıda /ñ/ ünsüzü için müstakil bir işaret kullanıldığından bahsedilebilir, ancak bunun da kesin olduğu söylenemez. Manihey yazıdaki YN veya NY şeklindeki yazımların Hamilton'un görüşünü desteklediği söylenebilir. ${ }^{8}$ Bunun dışında, Manihey yazıda, $\mathbf{N}$ veya $\mathbf{Y}$ harflerinin tek başına / ñ/ karşıllğıında olduğunu söylemek güçtür. Netice itibariyle, Eski Türkçenin yazı imkânları ölçüsünde /ñ/ ünsüzünün durumu hakkında kesin bir neticeye henüz ulaşılmamıştır.

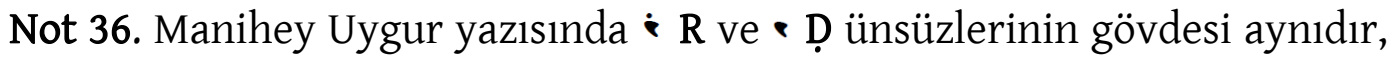
fark üzerine konan nokta ile sağlanmıştır. Bazı yazmalarda noktanın unutulmasıyla bu iki harfin birbirine karıştıııldığı görülüyor. Mesela, TḌS $\rightarrow$ TRS t(e)rs (U54 r4, neşir $\rightarrow$ satır 89). Karışıklığı önlemek amacıyla, bazı metinlerde R'nin yanına küçük bir nokta •• eklenebilir, mesela, M 919 numaralı parça (neşir $\rightarrow$ satır 37-44).

Not 37-38, 41. Manihey Uygur yazısında /s/, /ş/ ve /z/ ünsüzleri, s s, w Ş ve $\boldsymbol{Z} \mathbf{Z}$ olmak üzere üç farklı harf ile temsil edilse de harflerin birbirleri yerine kullanılmasına rastlanmaktadır. Ancak, İranî kökenli kelimelerde S harfinin /ş/'nin yazımında kullanılmaması düşündürücüdür (Hazai \& Zieme, 1970: 139140). Manihey yazıda, S’nin aynı zamanda /ş/ ve /z/, ş’nin /s/ ve Z'nin de /s/ karşllığında olabilmesi, Eski Türkçenin ağızları ile ilgili bir mesele olmalıdır.

Not 39-40. Manihey Soğdça metinlerde $6 /$ / $T$ ve $h$ T olmak üzere iki farklı harf mevcuttur. Bunlardan h T Tharfi arkaik bir imlânın bakiyesidir (Fariwar-Mohseni-Najafi, 2005: 124-125). \ T Ṭ harfi, Uygurca metinlerde az kullanılırken, /t/ için çoğu zaman 6 / $\mathbf{6}$ T kullanılmıştır. İki harfi birbirinden ayırmak amacıyla Uigurisches Wörterbuch'taki (Röhrborn, 2010: XXXVI) gibi h harfi için Ț işareti kullanılmıştır. Ayrıca, 6 / 6 T harfi Uygurca metinlerde satır

\footnotetext{
Manihey harfli M 157 (TM 515) numaralı parçanın arka yüzünün 6. satırında AAYNMAZ şeklinde yazılan fiili, Uigurisches Wörterbuch (Röhrborn, 2010: 116-117) ve Clark (2017: 226) ay(l)nmaz şeklinde okumuştur. Eski bir makalemde *añ- 'yok olmak, kaybolmak' diye bir fiilden bahsetmiştim (Uçar, 2018: 67-83). Manihey harfli metindeki imlâsına bakarak fiilin añmaz olarak okunabileceğini ve *añ- 'yok olmak, kaybolmak' ile ilişkilendirilebilineceğini düşünüyorum.
} 


\section{ग(৫)}

doldurucu harf olarak da vazife görmüş̧ür. ${ }^{9}$ Bk. U 34 r2, neşir $\rightarrow$ satır 46 . Böyle durumlarda harfin yazıçevrim satırına yansıtılmasına gerek yoktur.

Not 42. Manihey Uygur yazısında $\ddot{s}$ harfi /ç/ veya /c/ ünsüzünü karşllıyor olmalıdır (Röhrborn, 2010: XXXVII).

\section{IV. Örnek Metin Neşirleri}

Manihey harfli on üç parçanın harfçevrimi ve yazıçevrimi yukarıda önerilen tabloya göre hazırlanmıştır. Parçalar seçilirken yazımla ilgili yukarıdaki açıklamalara uygun örneklerin parçada bulunmasına dikkat edilmiştir. Parantez içindeki numara orijinal metindeki satır numarasını, en soldaki numara da buradaki neşir numarasını göstermektedir.

\section{Or. $8212 / 178^{10}$}

Aşağıdaki parça, Xwāstwānifft' in Londra yazmasına aittir. Parçanın neşri için bk. Clark, 2013: 14.

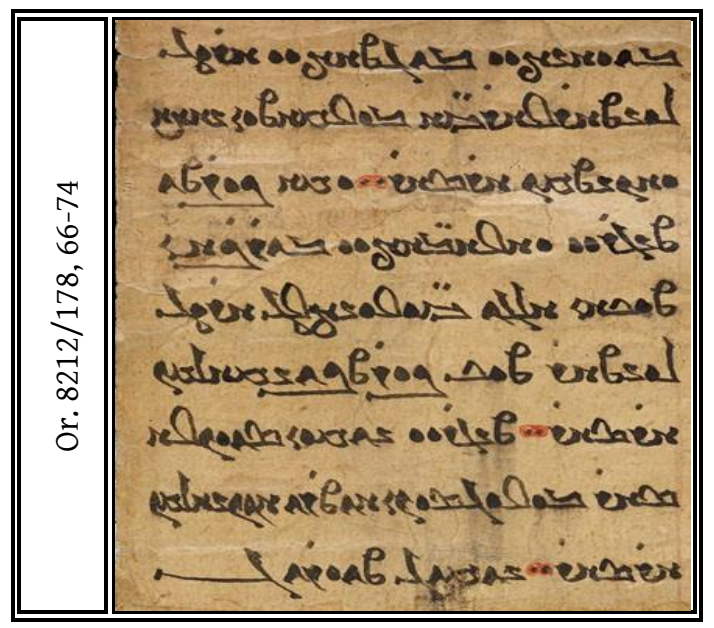

1 (66). BWYANÇYY BWGTAÇYY ARYĞ buyançı bögte $<$ gç̧i arı̆̆

2 (67). DYNTARLARẌA BYLMATYN NAÇA dindarlarqa bilmetin neçe

9 Harf, Manihey yazıda aynı zamanda sembolik dinî bir anlama da sahiptir. Bk. Tongerloo-Knüppel, 2014: 199-204.

10 Resim, IDB'nin (The International Dunhuang Project: The Silk Road Online) internet sitesinden (www.idp.bl.uk) alınmıştır. 


\section{0}

3 (68). YAZNTMZ ARSAR „, YMA KYRTW

yaz(1)nt(1)m(1)z erser ,y y(i)me $e^{11}$ kértü

4 (69). TNGRYY YALABACÇYY BWRḲAN

$\mathrm{t}(\mathrm{e})$ Đri yalavaçı burxan

5 (70). TYPAN ADGW ẌYLYNÇLĞ ARYĞ

tépen edgü q1lınçl(1) $\breve{g}$ arı̆̆

6 (71). DYNTAR TYP KYRTKWNMADMZ

dındar tép kértkünmad(i)m(i)z

7 (72). ARSAR „, TNGRYY NWMYN SWYZLA

erser „t(e)yri nomin sözle-

8 (73). SAR BYLYGSYZN AWTRW AWZNADMZ

ser biligsiz(i)n utru özned(i)m(i)z

9 (74). ARSAR „NWMWĞ TWYRWG , erser „nomuğ törüg ,

\section{Or. $8212 / 178^{12}$}

Aşağıdaki parça, yine Xwāstwānifft'in Londra yazmasına aittir. Parçanın neşri için bk. Clark, 2013: 20-21.

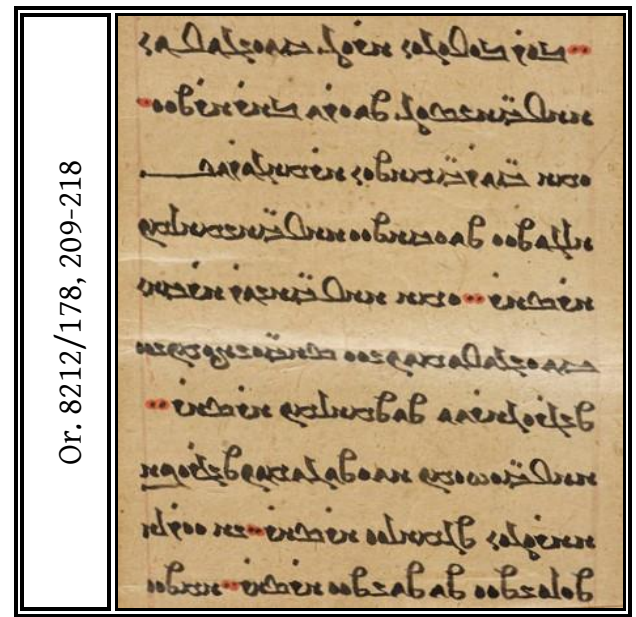

11 Edatın okunuşu ve kökeni sorununu ayrıntılı olarak başka bir makalemde ele alacağım.

12 Resim, IDB'nin (The International Dunhuang Project: The Silk Road Online) internet sitesinden (www.idp.bl.uk) alınmıştır. 


\section{J(ఠ)}

10 (209). „BYR BYLYGYN ARYĞ XWYNGWLWN

, bir biligin arığ könülün

11 (210). AALẌANSYĞ TWYRW BAR ARTYY ", alqansıq törü bar erti ,

12 (211). YMA ẌWRẌMATYN ARMAGWRWP y(i)me qorqmatın ermegürüp

13 (212). ADGWTYY TWYXATYY AALẌANMADMZ edgüti tüketi alqanmad(1)m(1)z

14 (213). ARSAR , YMA AALẌANWR ARXAN erser , $\mathrm{y}(\mathrm{i}) \mathrm{me}$ alqanur erken

15 (214). XWYNGWLWMWZNYY SAẌYNÇYMZNYY köyülümüzni saqınçım(1)znı

16 (215). TNGRYGARWW TWTMADMZ ARSAR " $\mathrm{t}(\mathrm{e})$ yrigerü tutmad(1) $\mathrm{m}(1) \mathrm{z}$ erser ,

17 (216). AALẌYŞYMZ AWYTWGWMWZ TNGRYKA alq1şım(1)z ötügümüz $t(e)$ yrike

18 (217). AARYĞYN TGMADYY ARSAR „NA YYRDA arığın $t(e)$ gmedi erser ", ne yérde

19 (218). TYDYNTYY TWTWNTYY ARSAR „AMTYY tidintı tutuntı erser , amt1

\section{U 11 (M 153/TM 303) $)^{13}$}

Aşağıdaki parça, Xwāstwānift' in Berlin yazmalarına aittir (Wilkens, 2000: 348-349). Parçanın neşri için bk. Clark, 2013: 46-47.

13 Resim, Berliner Turfan-Sammlung'un internet sitesinden (www.turfan.bbaw.de) alınmıștır. 


\section{J(৫)}

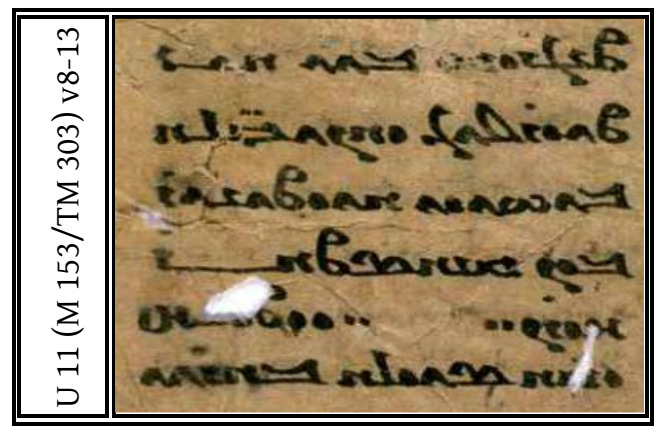

20 (8). TNGRYM BWW AWN

$\mathrm{t}(\mathrm{e})$ yrim bo on

21 (9). TWYRLWG YAZWẌDA

törlüg yazuqda

22 (10). BWŞWNW AWYTWNWR

boşunu ötünür

23 (11). BYZ MNASTAR

biz m(a)nāstār

24 (12). HYRZ „〈 > $\rangle$ YYT//Ç

hirz ", yét [in]ç

25 (13). YMA SWYDA BARWW

$\mathrm{y}(\mathrm{i}) m e$ söde berü

\section{MIK III 192 II (M 172) ${ }^{14}$}

Aşağıdaki parça, Xwāstwānīft'in Berlin yazmalarına aittir (Wilkens, 2000:

357). Parçanın neşri için bk. Clark, 2013: 52-53.

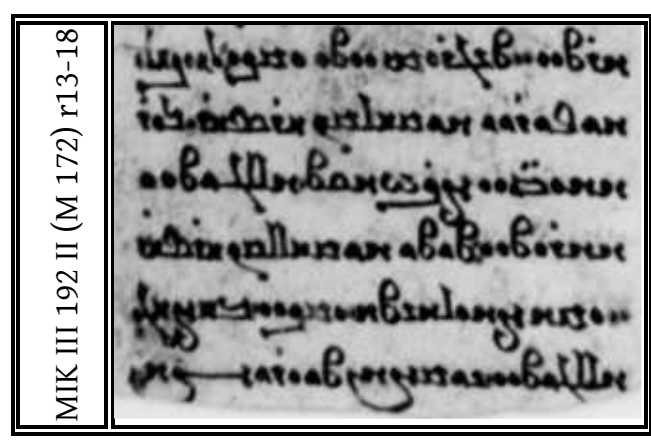

14 Resim, Berliner Turfan-Sammlung'un internet sitesinden (www.turfan.bbaw.de) alınmıştır. 


\section{Ј(ङ)}

26 (13). ARTYY , TNGRYM YYTY YMKY TWYKAṬY

erti „, t(e)Đrim yéti y(i)mki tüketi

27 (14). AWLWRWW AWMADMZ ARSAR , BYR

oluru umad(1)m(1)z erser , bir

28 (15). AAYẌYY ÇKŞAṔT ADDGWTYY

ayqı ç(a)xşap(a)t edgüti

29 (16). AARYTYY „TWTW AWMADDMZ ARSAR

arit1 „, tutu umad(1)m(1)z erser

30 (17). „ YMA ÇAYDANTA YYMKYY BAÇAĞ

"y(i)me çaydanta y(i)mki baçağ

31 (18). ADDGWTYY NWMÇA TWYRWÇA , edgüti nomça törüçe ,

\section{U 8 (T II D 172) $)^{15}$}

Aşağıdaki parça, Xwāstwānīft'in Berlin yazmalarına aittir (Wilkens, 2000:

342). Parçanın neşri için bk. Clark, 2013: 39-40.

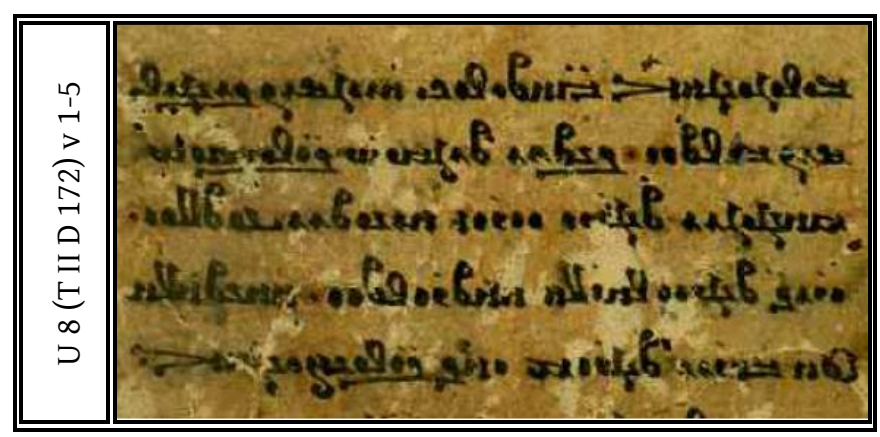

32 (1). BYLYGYNGAH ẌATYLYP AWGSWZ KWNGWL biligine qatılıp ögsüz könül-

33 (2). SWZ XLTYY , KNTWW TWĞMYŞ KYYYNMYŞ süz k(e)lti , k(e)ntü tuğmış q1lınmış

34 (3). MANGYGWW TNGRYY YYRYN AWNYTWW EYTDDYY

15 Resim, Berliner Turfan-Sammlung'un internet sitesinden (www.turfan.bbaw.de) alınmıştır. 


\section{J曰)}

meygü t(e)yri yérin unıtu ıddı

35 (4). YRWK TNGRYY LARDA AATRYLTYY, AANTADDA

$y(a)$ ruq $t(e)$ yrilerde adriltı , antada ${ }^{16}$

36 (5). $\{$ TA $\}$ BARWW TNGRYM YAK KYLYNÇYNGA H

berü t(e)Đrim yek qilınçıøa

\section{M 919 (TM 417) ${ }^{17}$}

Wilkens, parçadaki Manihey yazının tuhaf dişlere sahip harflerden oluştuğunu belirtmiştir (2000: 314-315). Parçanın neşri için bk. Clark, 2017: 197203. Uygurca metin, Maniheizim'in kabul edildiği dönemde bir Uygur kağanının tahta çıkışını anlatmaktadır.

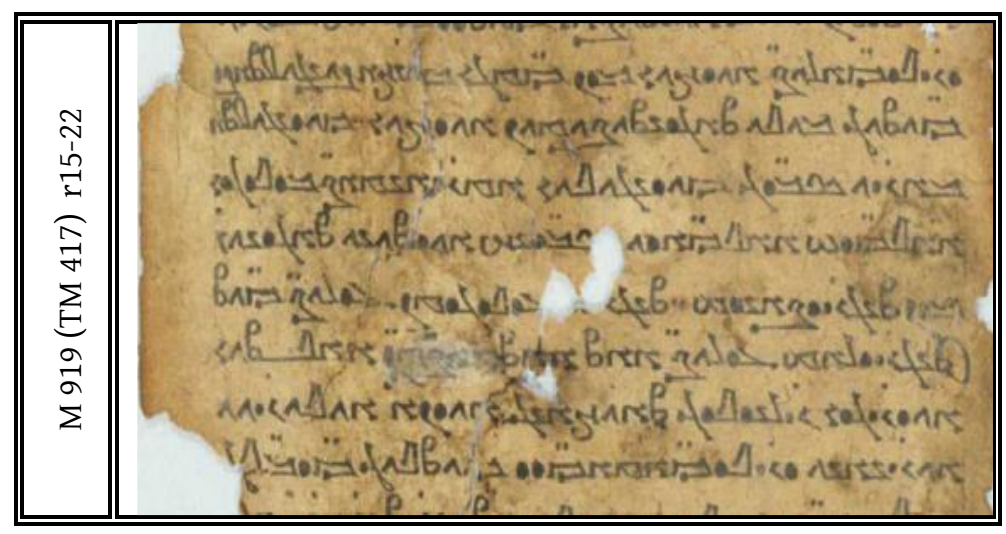

37 (15). YRLYẌADWK AWYÇWN BYZ ẌMĞN BARÇA KWNGWLTAKY

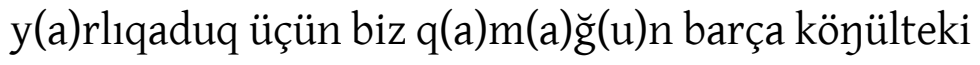

38 (16). ẌWTWĞ BWLW TAGYNTWKWMWZ AWYÇWN „, XWYNGWLTA qutuğ bulu tegintükümüz üçün , köyülte

39 (17). BARW SBYG XWYNGWLWN AMRANMAK BYLYGYN

16 AANTADDATA'nın yazımı sorunludur. Ne Xwāstwānifft'in diğer yazmalarında ne de başka bir Eski Uygurca metinde bu şekilde yazılan bir kelimeye rastlanmaktadır. Böyle bir kelime Eski Türkçe için tekörnek özelliğindedir. İlk kez Bang'ın (1923: 179) fark ettiği üzere 5. satırın başındaki TA muhtemelen bir dittography olmalıdır. Uigurisches Wörterbuch'a antadata şeklinde bir kelime madde olarak girmiştir (Röhrborn, 2015a: 179-180). Clark, neşrinde (2013: 40) 5. satırdaki TA'yı yazım fazlalı̆̆1 olarak işaretlemiştir. U 8 numaralı parçadaki kelime antada kelimesinden başka bir şey değildir.

17 Resim, Berliner Turfan-Sammlung'un internet sitesinden (www.turfan.bbaw.de) alınmıştır. 


\section{J(৫)}

berü s(e)vig köyülün amranmaq biligin

40 (18). AALẌYŞ AALẌAYW SBYNÇ AWYTWNW TAGYNWR alqiş alqayu s(e)vinç ötünü teginür

41 (19). BYZ TNGRYKANYM „TNGR/ EYLYGYMZ EYDWK ẌWT biz $\mathrm{t}(\mathrm{e})$ Đrikenim „, $\mathrm{t}(\mathrm{e}) \operatorname{\eta r}[\mathrm{i}]$ éligim(i)z ıduq qut

42 (20). TNGRYDAM EYDWK

$\mathrm{t}(\mathrm{e})$ yridem 1 duq at atamaq $(1) \mathrm{m}(1) \mathrm{z}$ altun

43 (21). AWYRGYN RDNYLYG TAWÇANG AWYZA AWLWRWW ör(i)gin r(e)dnilig tauçay üze oluru

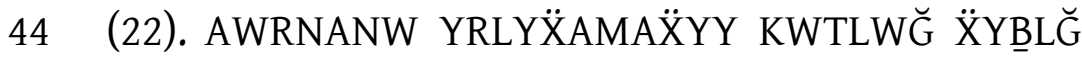
ornanu y(a)rlıqamaq1 kutluğ ${ }^{18}$ (düz. qutluğ) qıvl(1) $\breve{g}$

\section{U 34 ([T II] D 178) $)^{19}$}

Parçanın neşri için bk. Clark, 2013: 201-205. Uygurca parça, bir Manihey ilahiye aittir (Wilkens, 2000: 197-198).

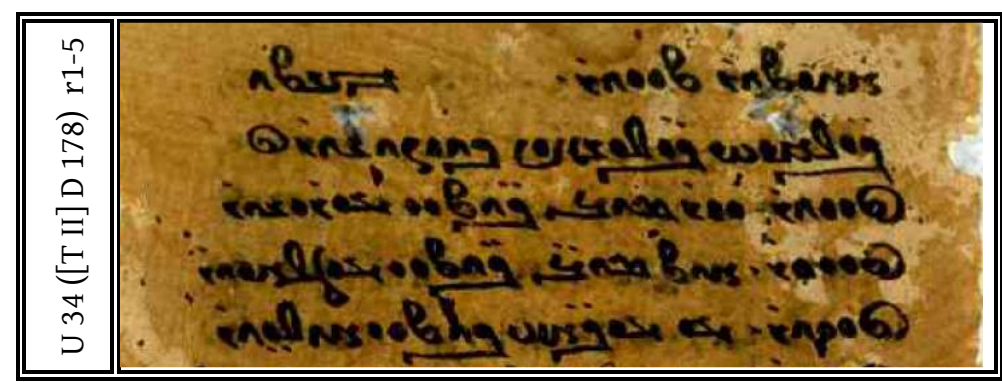

45 (1). AAYTWR TYYWR , < > XNTW aytur téyür , k(e)ntü

46 (2). KYLMYŞ KYYLNÇY KWYZWNWR T qılmış q1lınçı közünür

18 Yırtık nedeniyle K'nin üzerindeki noktalar görülemiyor (Clark, 2017: 198) veya müstensih harfin noktalarını unutmuş.

19 Resim, Berliner Turfan-Sammlung'un internet sitesinden (www.turfan.bbaw.de) alınmıştır. 


\section{J(৫)}

téyür yér sub qutı érinür

48 (4). TYYWR AWT SWB KWTYY EYĞLAYWR

téyür ot suv qutı ığlayur

49 (5). TYYWR EY EYKKAÇ KWTYY AWLYWR

téyür 1 1qaç kut ${ }^{20}$ (düz. qutı) ul(1)yur

\section{MIK III 201 I ([T II] D 176)}

Aşağıdaki parça, bir anlatıya aittir (Wilkens, 2000: 50-51). Parçanın daha önceki neşri ve resimler için bk. Le Coq, 1911: 5-7, Taf. I. Orijinal metin için Le Coq'un yeniden Manihey harflerine döktüğü metin (soldaki) ile yine onun yayımladığı resimler (sağdaki) kullanılmıştır.
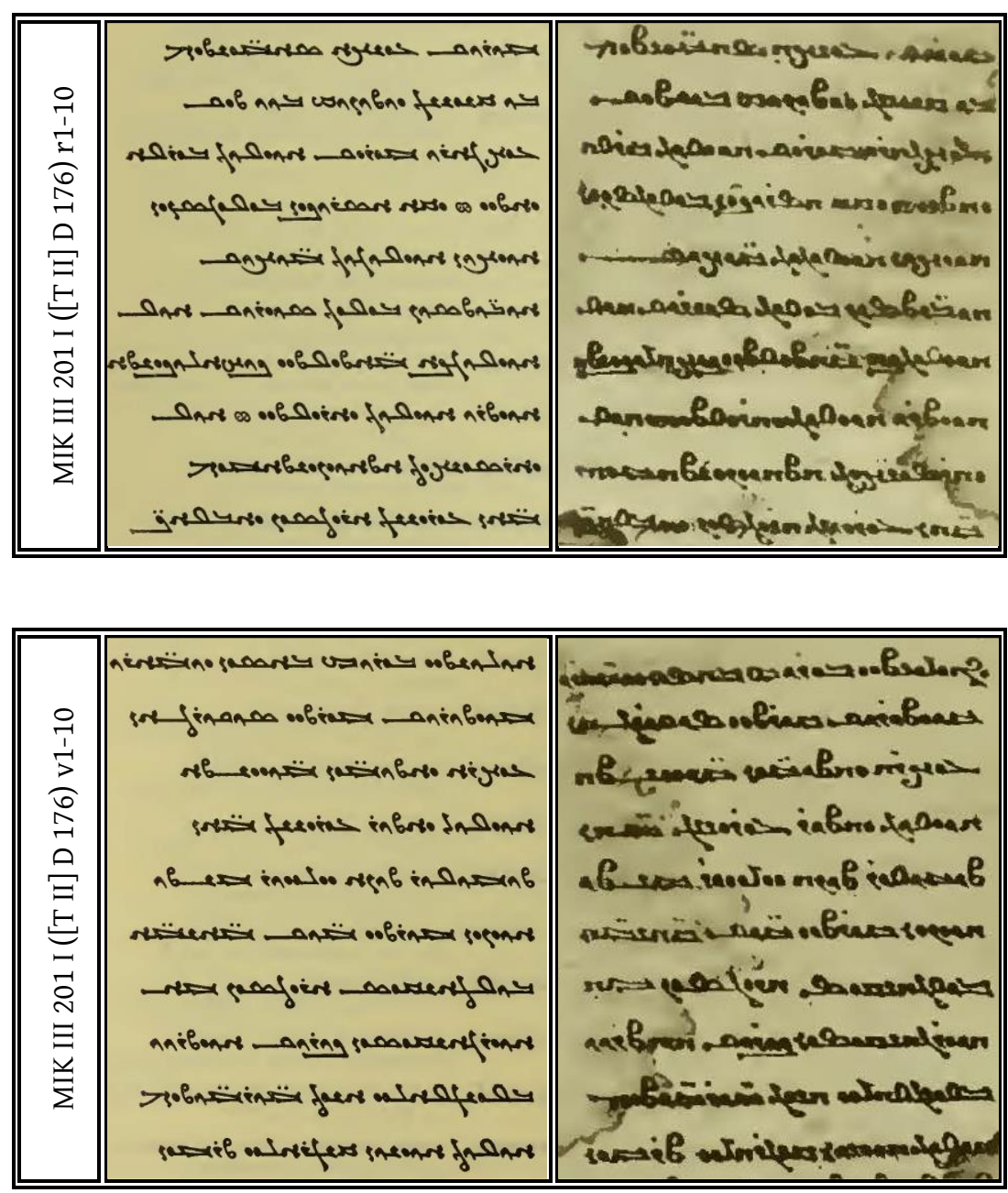

20 Müstensih, K'nin noktalarını koymayı unutmuş olmalıdır. 


\section{1)}

\section{Ön}

50 (1). XWYRWP EYNÇA SAẌYNTY H körüp inçe saqıntı

51 (2). BW MNYNNG YWTWZWM BWW TYP bo m(e)nin yutuzum bo tép

52 (3). EYÇGARW XYRYP AWYLWG BYRLA içgerü kirip ölüg birle

53 (4). YATYY „YMA ASRWKYN BYLYGSZYN yat $<\mathrm{t}>1, y(\mathrm{i})$ me esrükin biligs(i)zin

54 (5). AWYÇWN AWYLWGWG ẌWÇWP üçün ölügüg qoçup

55 (6). AWBWTSWZ BYLYG SWYRWP AWL uvutsuz bilig sürüp ol

56 (7). AWYLWGKA ẌATYLTYY KWÇADWKYNTA ölügke qatıltı küçedükinte

57 (8). AWYTRW AWYLWG YARYLTYY „AWL ötrü ölüg yarıltı „ol

58 (9). YARSYNÇYĞ ATAWYZYNTAXY H yarsınçı̆̆ etözinteki

59 (10). ẌAN EYRYNNG ARYĞSYZ YABLAẌ qan irin arı̆̆sız yablaq

\section{Arka}

60 (1). AWDWNTYY BYRWX BASYN YWẌARW uduntı birök başın yuqaru

61 (2). XWYTWRWP XYRTYY SWPWRĞAN kötürüp kirti supurğan 


\section{J(ఠ)}

62 (3). EYÇRA YATWẌYN ẌWYYNTA içre yat<t>uqun qoyınta

63 (4). AWYLWG YATWR EYRYNNG ẌAN ölüg yatur irin qan

64 (5). TWXWLWR TWZA YYDYYWR XNTW tökülür toza yıdıyur k(e)ntü

65 (6). AWYZYN XWRTYY ẌWP ẌANẌA özin körti qop qanqa

66 (7). BWLĞANMYS ARYĞSYZ XA bulğanmış arı̆̆sızke (düz. arı̆̆sızqa)

67 (8). AWYRGANMYSYN KWRWP AWTRWW örgenmişin körüp ötrü

68 (9). BLYNGLADYY ANYĞ ẌWRẌWTY H $\mathrm{b}(\mathrm{e})$ linledi anı $\breve{g}$ qorqutı

69 (10). AWLWĞ AWYNWN MNGRADYY TRXYN uluğ ünün $\mathrm{m}(\mathrm{a})$ yradı $\mathrm{t}(\mathrm{e}) \mathrm{rkin}$

\section{U 46a (T II D 172)}

Parçanın neşri için bk. Le Coq, 1922: 14. Uygurca parça, bir anlatıya aittir (Wilkens, 2000: 99-100).

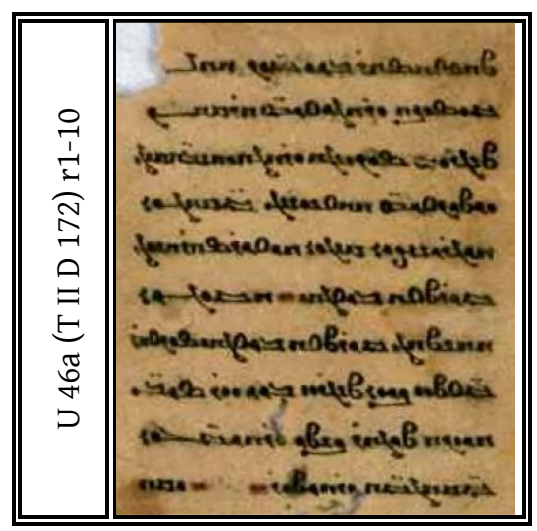

${ }^{21}$ Resim, Berliner Turfan-Sammlung'un internet sitesinden (www.turfan.bbaw.de) alınmıştır. 


\section{ग(ब)}

70 (1). TAPLASAR BWW ẌYZ AAD// taplasar bo q1z ad[1n]

71 (2). XYSYKA YRAĞWLWẌ ARMAZ kişike y(a)rağuluq ermez

72 (3). TNGRYM SYZYNGA YRAĞAY ANBAMYĞ $t(e)$ yrim sizine y(a)rağay anvamı̆̆

73 (4). YWTWZLWẌ AALNYNNG ẌMAĞWN yutuzluq alnın $q(a)$ mağun

74 (5). AWGRWNÇWN MNGYN AWLWRSAR ANYĞ ögrünçün m(e)yin olursar anı̆̆

75 (6). XWRTLA BWLĞAY „AXYGWN körtle bolğay „, ekigün

76 (7). AANTAĞ XWRTLA BWLĞAYSYZLAR antağ körtle bolğaysızlar

77 (8). ẌLTYY KWYN TNGRYY BWW YYR SWV $q(a) l t ı$ kün $t(e)$ yri bo yér suv

78 (9). AWYZA TWĞAR KNTW YRAWẌEYN üze tuğar k(e)ntü y(a)ruqın

79 (10). ẌMAĞẌA YRAWTWR „, „YMA q(a)mağqa y(a)rutur ", ,y(i)me

\section{M $157($ TM 515) 22}

Parçanın neşri için bk. Clark, 2017: 225-226. Uygurca parça, dinî bir vaaza aittir (Wilkens, 2000: 151).

${ }^{22}$ Resim, Berliner Turfan-Sammlung'un internet sitesinden (www.turfan.bbaw.de) alınmıştır. 


\section{J(ङ)}

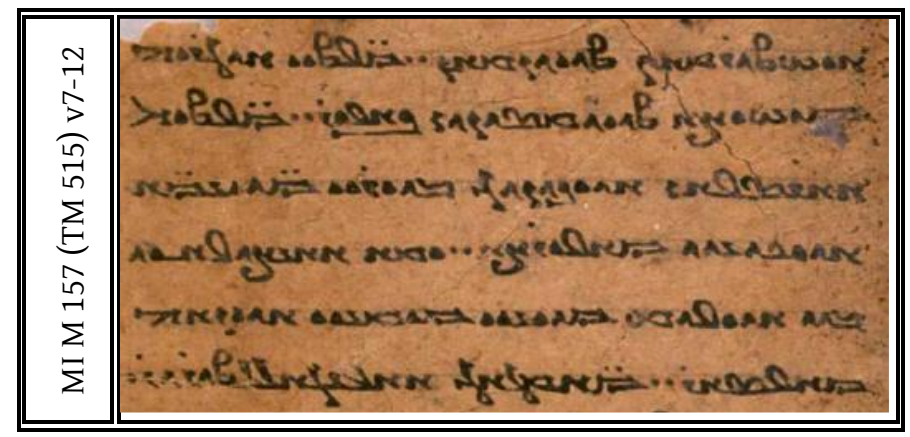

80 (7). AYŞTWRMAZ TWYWZMAZ „ ẌALTYY AWĞRYH éştürmez tuyuzmaz „q q(a)ltı oğrı

81 (8). XYŞYÇA TWYWMSWZWN KALYR „ ẌLTYH kişiçe tuyumsuzun kelir „, q(a)ltı

82 (9). AARSLAN AWYKWZWG BWYRYY ẌWYNẌA arslan öküzüg böri qoñqa

83 (10). AWYPWNWW XALYRÇA „, YMA AANÇWLAYW öpünü kelirçe „, y(i)me ançulayu

84 (11). BWW AWYLWM XWYNYY XYMNYY AWYZAH bo ölüm küni kimni üze

85 (12). XALSAR „ ẌAMĞAĞ AALNGADDTWRWR , kelser „ qam(a) ğă̆ alyadturur ,

\section{U 54 (T II D 178) ${ }^{23}$}

Parçanın neşri için bk. Clark, 2013: 206-210. Uygurca parça, bir Manihey ilahiye aittir (Wilkens, 2000: 140-141).

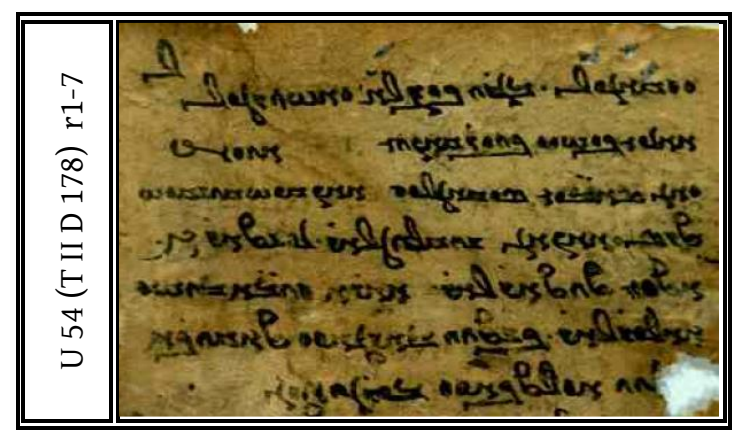

${ }^{23}$ Resim, Berliner Turfan-Sammlung'un internet sitesinden (www.turfan.bbaw.de) alınmıştır. 


\section{1)}

86 (1). YYMAGYL , BAGRW KYZLA , YAŞWRĞYL L yémegil , bekrü kizle , yaşurğıl

87

(2). AADYN KYŞYY KWYRMAZWN 〈 > AWYÇ adın kişi körmezün üç

88 (3). YAG SABYYN SYMAĞLYY 〈 > AAZMYŞ MWNMYŞ yeg savin sımağ $1_{1}^{24}$ azmış munmış

89 (4). TḌS, AAZAG NWMLWĞLAR, DYNTAR A $\operatorname{tḍ~s}^{25}$ (düz.t(e)rs) $\operatorname{azag}^{26}$ (düz. ază̆) nomluğlar , dındar

90 (5). ATYN TWTARLAR, 〈 > AARA YWB̈A BWŞY atın tutarlar , ara yuva buşi

91 (6). AALYRLAR , KNTWW BARĞAYY TAMUḲA alırlar, k(e)ntü barğay tamuxa ${ }^{27}$ (düz. tamuqa)

92 (7). //DWW AYLTKAYY BYRGWÇYG 〈 >, [u]du éltgey bérgüçig ,

\section{U $55($ TM 512) 28}

Parçanın neşri için bk. Clark, 2013: 188-189. Uygurca parça, bir Manihey ilahiye aittir (Wilkens, 2000: 317-318).

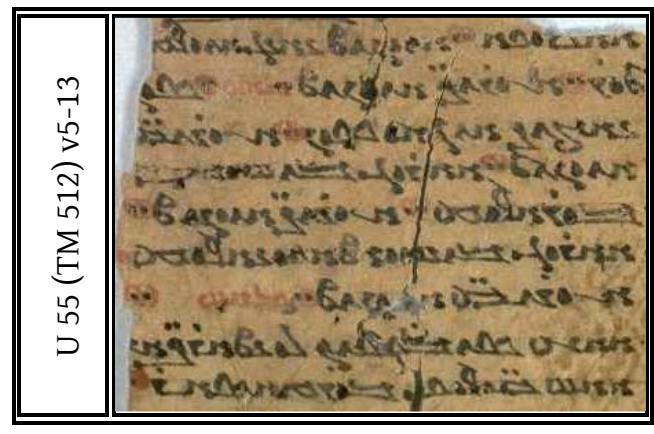

24 Clark, kelimeyi sımağıl 'kırma' ile düzeltip okumuştur (2013: 208).

25 Müstensih, R'nin noktasını koymayı unutmuş olmalıdır.

26 Müstensih, Ğ yerine yanlışlıkla G yazmış olmalıdır.

27 Müstensih, K’’nin ikinci noktasını koymayı unutmuş olmalıdır.

28 Resim, Berliner Turfan-Sammlung'un internet sitesinden (www.turfan.bbaw.de) alınmıştır. 


\section{ग(ब)}

93 (5). AADRYPA "AWYZWT NANG AWYLM//

adrıpa $<$ n> , üzüt ney ölm[ez]

94 (6). TYR „A YRWK AWYZWT „BAŞ „SYZ

tér „ a y(a)ruqüzüt , baş „ siz

95 (7). NAÇWK AWĞAY SYZ „A YRWẌ

neçük uğay siz „, a y(a)ruq

96 (8). AWYZWT „AARYĞ BWŞY H

üzüt , arı̆̆ buşi

97 (9). BYRALYM „A YRWK AWYZWT ”

bérelim "a y(a)ruq üzüt ,

98 (10). AARYĞ BWŞYN TAPYNALYM , arı̆̆ buşin tapınalım ,

99 (11). A YRWẌ A/YZWT „BAŞ „, a y(a)ruq üzüt , baş ,

100 (12). AAÇ SUBSWZZ DYNTARKֵA

aç suvsuz dindarqa

101 (13). AAŞ ẌYLYP BYRMASAR ” aş q1lip bérmeser ",

\section{U 74 (M 748/TM 152/TM 152a/TM 158/TM 181a) ${ }^{29}$}

Parçanın neşri için bk. Zieme, 1997: 186-189. Uygurca parça, "Ruh Üzerine Vaaz" isimli eserin tercümesine aittir (Wilkens, 2000: 169-170).

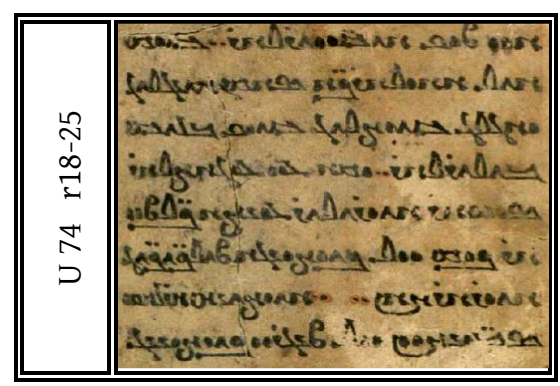

29 Resim, Berliner Turfan-Sammlung'un internet sitesinden (www.turfan.bbaw.de) alınmıştır. 


\section{ग(ఱ)}

102 (18). AAY TYP AWẌYYWRLAR „, KYM

ay tép oquyurlar „, kim

103 (19). AWL AAYLARKA SAMZ AWNGLWG

ol aylarqa sem(i)z öylüg

104 (20). YAĞLĞ XWÇLWG XWYP BDWX

yağl(1) ğ küçlüg köp b(e)dük

105 (21). BWLWRLAR „YMA EYY EYĞAÇLAR

bolurlar , y(i)me 1 1̆̆açlar

106 (22). SYŞAR AWYRWLWR EYNÇA KLTYY

sişer ürülür inçe $q(a) l t ı$

107 (23). AR KYM YYL KWYÇYNGA TWLKWWKWĞ

er kim yél küçine tolququğ

108 (24). AWYRARÇA „ „AWYÇWNÇ ARDAM

ürerçe ", üçünç erdem

109 (25). SB̊YNÇYY YYL TNGRYY KWYÇYNNG

s(e)vinç yél t(e)Đri küçin

\section{Sonuç}

Harfçevrim ve yazıçevrim tablosu hakkındaki bazı önemli noktaları kısaca vurgulamak faydalı olacaktır:

1. Yukarıdaki önerilen tablo, Manihey harfli Uygurca metnin harfçevriminin ve yazıçevriminin birlikte verildiği bir neşirde kullanılmak üzere tasarlanmıştır. Mesela, orijinal metinde /ş/ ve /z/'nin yazımında S harfi, ya da /s/'nin yazımında $\mathrm{Z}$ veya \$̧, /d/'nin yazımında T, /b/'nin yazımında P, /q/'nın yazımında $\mathrm{K}$ harfi kullanılmış olsun. Bu yazımlar, harfçevrim satırında görüleceği için bunların farklı işaretlerle yazıçevrimde ayrıca gösterilmesine gerek kalmayacaktır. Metnin harfçevrimini vermeden neşrinde bunları gösterecek biri ekstra işaretler kullanmak zorunda kalacaktır.

2. Uygur harfli metinlerde elif harfinin harfçevrimi için sembol yerine bir harfin kullanılması gerektiğinden daha önce bahsetmiştim (2020: 245). Manihey 


\section{J(৫)}

harfli metinlerde de aynı şekilde elif harfinin harfçevrimi için sembol yerine, Latin yazısındaki A harfinin kullanılması gerektiğini burada tekrar vurgulamalıyım. Zira transliteration veya harfçevrim, bir yazıdaki "harfleri" başka bir yazıya "harflerle" aktarma işiyse, bunun için aktarılan yazıdaki "harflerin" kullanılması elbette daha doğru olacaktır.

3. Uygur harfli metinlerin neşrinde orijinal metinde yazılmayan ünlülerin yazıçevrimde gösterilme tercihinin nâşire bırakılabileceğinden bahsetmiştim (2020: 245). Ayı durum Manihey harfli metinlerin neşri için de geçerlidir. Ancak, yazılmayan ünlülerin yazıçevrimde parantez içinde ayrıca gösterilmesinin okuyucu açısından faydalı olabileceğini düşünüyorum.

4. Manihey yazıda, AWY, AY ve WY'nin bir hece karşılığında da olabileceği tabloda belirtilmemiştir, çünkü bu harf guruplarının aynı zamanda bir hece karşılığında olabileceğini nâşirin bilememesi mümkün değildir.

5. Manihey yazıda, W ve $\mathbf{Y}$ gibi harflerin kelime ortasında ve sonunda, çoğunlukla da satırın sonuna yakın yerlerde çift olarak yazıldığı görülüyor. $\mathrm{H}$ ve T harfleri de satır doldurucu olarak kullanılmıştır. Bu yazımların nedeni büyük ihtimalle estetik gayeyle satırların düzgün görünmesini sağlamak içindir. Belki de DD, NNG ve NNK şeklindeki yazımların nedeni de bu olabilir. Böyle yazımların sadece harfçevrimde gösterilmesi, yazıçevrime yansıtılmaması gerekmektedir, çünkü bu yazım tercihlerinin metnin yazıçevrimiyle bir ilgisi yoktur.

6. Manihey harfli metnin harfçevriminin üst satırda büyük harflerle, yazıçevriminin alt satırda küçük harflerle gösterilmesinin okuyucu açısından daha faydalı olacağı kesindir. Uygur harfli metinler için de bu uygulamanın yararlı olabileceğini belirtmiştim (2020: 245). Zaten, müteveffa Fıransız Uygurist J. R. Hamilton bunu yıllar öncesinde neşirlerinde uygulamıştır. Neşirde harfçevrimin verilmesinin birçok amacı vardır. Bunların en başında okuyucunun metnin aslıyla irtibatının kolayca sağlaması gelmektedir. Harfçevrim için büyük harflerin kullanılmasıyla okuyucu bu irtibatı şüphesiz daha kolay sağlayacaktır. Ayrıca, okuyucu harfçevrim ile yazıçevrimi birbirinden daha net biçimde ayırabilecektir.

7. Manihey yazıda ünsüzleri gösteren bazı harflerin gövdesi aynıdır. Yazı, aynı gövdeye sahip harflerde harfin üzerine tek veya çift nokta koyarak farkı sağlamıştır. Bu tür harflerin harfçevrimi için Latin yazısında yine aynı gövdeye 
sahip olanlar tercih edilmiştir. Böylelikle Manihey harflerini öğreneceklerin ve okuyacakların harfin aslıyla daha kolay irtibat kurması hedeflenmiştir.

\section{Kaynakça}

Ariz, E. (2011). Bibliographie der in der VR China verfassten Arbeiten über den Manichäismus. In Özertural, Z. \& Wilkens, J. (Eds.), Der östliche Manichäismus, Gattungsund Werksgeschichte, Vorträge des Göttinger Symposiums vom 4./5. März 2010 (pp. 193-222). De Gruyter.

Bang, W. (1923). Manichaeische Laien-Beichtspiegel. Le Muséon, 36, 137-142.

Clark, L. (1982). The Manichean Turkic Pothi-Book. Altorientalische Forschungen, 9, 145-218.

Clark, L. (1997). The Turkic Manichaean Literature. In Mirecki, P. \& BeDuhn, J. (Eds.), Emerging from Darkness: Studies in the Recovery of Manichaean Sources (pp. 89-141). Brill.

Clark, L. (2013). Uygur Manichaean Texts, Texts-Translations-Commentary II: Liturgical Texts. Brepols Publishers.

Clark, L. (2017). Uygur Manichaean Texts, Texts-Translations-Commentary III: Ecclesiastical Texts. Brepols Publishers.

Clauson, Sir G. (1962). Turkish and Mongolian Studies. Royal Asiatic Society of Great Britain and Ireland.

Clauson, Sir G. (1972). An Etymological Dictionary of Pre-Thirteenth Century Turkish. Oxford University Press.

Durkin-Meisterernst, D. (2000). Erfand Mani die manichäische Schrift? In Emmerick, R. E. et al. (Eds.), Studia Manichaica, IV. Internationaler Kongreß zum Manichäismus, Berlin 14.-18. Juli 1997 (pp. 161-178). De Gruyter.

Durkin-Meisterernst, D. (2014). Grammatik des Westmitteliranischen (Parthisch und Mittelpersisch). Verlag der Österreichischen Akademie der Wissenschaften.

Erdal, M. (1991). Old Turkic Word Formation, a Functional Approach to the Lexicon I-II. Harrassowitz Verlag.

Erdal, M. (2004). A Grammar of Old Turkic. E. J. Brill.

Fariwar-Mohseni-Najafi, J. (2005). Die manichäische Schrift der mitteliranischen Sprachen. Peter Lang Europäischer Verlag der Wissenschaften. 
Fedakâr, D. (1991). Das Alttürkische in sogdischer Schrift Textmaterial und Orthographie (Teil I). Ural-Altaische Jahrbücher: Neue Folge, 10, 85-98.

Hamilton, J. R. (1971). Manuscrits ouïgours de Touen-Houang, le conte bouddhique du bon et du mauvais prince en version ouigoure: manuscrits ouïgours de Touen-Houang. Klincksieck.

Hazai, G. \& Zieme, P. (1970). Zu einigen Fragen der Bearbeitung türkischer Sprachdenkmäler. Acta Orientalia, 32, 125-140.

Henning, W. B. (1958). Mitteliranisch. In Spuler, B. (Ed.), Handbuch der Orientalistik: İranistik (pp. 20-130). E. J. Brill.

Kara, G. (1996). Aramaic Scripts for Altaic Languages. In Daniels, P. T. \& Bright, W. (Eds.), The World's Writing Systems (pp. 536-558). Oxford University Press.

Knüppel, M. (2002). Zu -"/-ww/-yy in manichäisch-türkischen Texten. Materialia Turcica, 23, 45-52.

Knüppel, M. (2014). Betrachtungen zum zeilenfüllenden $\mathrm{H}$ im «Manichäischen Pothī-Buch». In Mirsultan, A. et al. (Eds.), Eski Türkçeden Çă̆daş Uygurcaya, Mirsultan Usman'in Doğumunun 85. Yllına Armağan (pp. 163-165). Kömen Yayınları.

Le Coq, A. von (1909). Köktürkisches aus Turfan. (Manuskriptfragmente in köktürkischen „Runen“ aus Toyoq und Idiqut-Schähri [Oase von Turfan]). Sitzungberichte der Königlich Preussischen Akademie der Wissenschaften (pp. 1047-1061).

Le Coq, A. von (1911). Türkische Manichaica aus Chotscho I. Abhandlungen der Königlich Preußischen Akademie der Wissenschaften.

Le Coq, A. von (1922). Türkische Manichaica aus Chotscho III: nebst einem christlichen Bruchstück aus Bulayıq. Abhandlungen der Königlich Preußischen Akademie der Wissenschaften.

Lidzbarski, M. (1916). Die Herkunft der manichäischen Schrift. Sitzungsberichte der Königlich Preussischen Akademie der Wissenschaften (pp. 1213-1222).

Moriyasu, T. (1991). ウイグル=マニ教史の研究 [A Study on the History of Uighur Manichaeism: Research on Some Manichaean Materials and their Historical Background]. 大阪大学文学部紀要 [Memoirs of the Faculty of Letters Osaka University], 31-32, 1-248.

Moriyasu, T. (2004). Die Geschichte des uigurischen Manichäismus an der Seidenstraße: Forschungen zu manichäischen Quellen und ihrem geschichtlichen Hintergrund. Übers. von Ch. Steineck. Harrassowitz Verlag. 
Müller, F. W. K. (1904a). Handschriften-Reste in Estrangelo-Schrift aus Turfan, Chinesisch-Turkestan [I]. Sitzungsberichte der Königlich Preußischen Akademie der Wissenschaften (pp. 348-352).

Müller, F. W. K. (1904b). Handschriften-Reste in Estrangelo-Schrift aus Turfan, Chinesisch-Turkestan II. Abhandlungen der Königlich Preußischen Akademie der Wissenschaften (pp. 1-117).

Röhrborn, K. (1983). Zu einem dialekt-differenzierenden Lautübergang im Alttürkischen. Materialia Turcica, 7/8, 295-305.

Röhrborn, K. (2010). Uigurisches Wörterbuch, Sprachmaterial der vorislamischen türkischen Texte aus Zentralasien I/1: ab- äzüglä-. Franz Steiner Verlag.

Röhrborn, K. (2015a). Uigurisches Wörterbuch, Sprachmaterial der vorislamischen türkischen Texte aus Zentralasien II/1: a-asvık. Franz Steiner Verlag.

Röhrborn, K. (2015b). Clark, Larry: Uygur Manichaean Texts. Texts, Translations, Commentary. Volume II: Liturgical Texts. Turnhout: Brepols 2013. X, 372 S. $4^{\circ} 1 / 4$ Corpus Fontium Manichaeorum. Series Turcica 2. Lw. € 100,00. ISBN 978-2-503-55024-4. Orientalistische Literaturzeitung, 110(2), 169-171. (Rezension)

Röhrborn, K. (2016). Turkologie, Iranistik und das Uigurische Wörterbuch. In Hauenschild, I. et al. (Eds.), Eine hundertblättrige Tulpe: Bir șadbarg lāla, Festgabe für Claus Schönig (pp. 389-396). Klaus Schwarz Verlag.

Röhrborn, K. (2018). Die Umschrift des Uigurischen: die Berliner Schulen und das uigurische Wörterbuch. In Gulácsi, Z. (Ed.), Language, Society, and Religion in the World of the Turks, Festschrift for Larry Clark at Seventy-Five (pp. 99-115). Brepols Publishers.

Semet, A. (2011). Die chinesischen Forschungen zum iranischen und zum uigurischen Manichäismus. In Özertural, Z. \& Wilkens, J. (Eds.), Der östliche Manichäismus, Gattungs- und Werksgeschichte, Vorträge des Göttinger Symposiums vom 4./5. März 2010 (pp. 223-234). De Gruyter.

Skjaervø, P. O. (1996). Aramaic Scripts for Iranian Languages. In Daniels, P. T. \& Bright, W. (Eds.), The World's Writing Systems (pp. 515-535). Oxford University Press.

Sundermann, W. (1985). Schriftsysteme und Alphabete im alten İran. Altorientalische Forschungen, 12(1), 101-113.

Tekin, Ş. (1963). Mani Dininin Uygurlar Tarafından Devlet Dini Olarak Kabul Edilişinin 1200. Yıldönümü Dolayısı İle Birkaç Not (762-1962). Türk Dili Araştırmaları Yıllı̆̆ Belleten 1962, 1-11. 


\section{1)}

Tekin, T. (1984). Çeşitli Alfabelerle Türkçe Yazılar: Manihey Alfabesiyle Türkçe. Tarih ve Toplum, 116, 6-10 (390-395).

Tongerloo, A. van \& Knüppel, M. (2014). Schriftsymbolistische Deutungen der Verwendung des Graphems ta in manichäischer Schrift. Wiener Zeitschrift für die Kunde des Morgenlandes, 104, 199-204.

Uçar, E. (2018). Bilge Kagan (Doğu 41) Yazıtındaki NIñTYn İbaresi Üzerine. Journal of Old Turkic Studies, 2(1), 67-83.

Uçar, E. (2020). Türkiye'deki Eski Uygurca Metin Neşirleri İçin Kullanılacak Harfçevrim ve Yazıçevrim Kilavuzu. Journal of Old Turkic Studies, 4(1), 231-250.

Volker, A. et al. (2000). Bibliographie alttürkischer Studien. Ausgewählt und chronologisch angeordnet. Nebst einem Anhang: Alphabetisches Siglenverzeichnis zu Klaus Röhrborn: Uigurisches Wörterbuch, Lieferung 1-6 (1977-1998). Harrassowitz Verlag.

Wilkens, J. (2000). Alttürkische Handschriften Teil 8: Manichäisch-türkische Texte der Berliner Turfansammlung. Verzeichnis der Orientalischen Handschriften XIII/16. Franz Steiner Verlag.

Zieme, P. (1969). Unterschungen zur Schrift und Sprache der manihäisch-türkischen Turfantexte. Humboldt-Universität Berlin. (ungedruckte Dissertation)

Zieme, P. (1975). Manichäisch-türkische Texte, Texte, Übersetzung, Anmerkungen, mit 178 Faksimiles auf 56 Tafeln. Berliner Turfantexte 5. Akademie Verlag.

Zieme, P. (1997). VIII. Anhang: Ein türkisches Fragment des "Sermons von der Seele" (Windgott). In Sundermann, W. (Ed.), Der Sermon vom Licht-Nous (pp. 186-189). Berliner Turfantexte 17. Brepols Publishers. 